Review

\title{
The Therapeutic Effects of Acupuncture and Electro- acupuncture on Cancer-related Symptoms and Side-Effects
}

\author{
Qiu-Qin Han ${ }^{1,2,3}$, Yi Fu ${ }^{1,2,3}$, Jia-Mei Le ${ }^{1,2,3}$, Yu-Jie Ma1,2,3, Xin-Dong Wei ${ }^{1,2,3}$, Hou-Lin Ji1,2,3, Haochen Jiang ${ }^{4,5}$, \\ Yueqiu Gao ${ }^{4,5}$ and Hailong $\mathrm{Wu}^{1,2,3}$ \\ 1. Shanghai University of Medicine \& Health Sciences Affiliated Zhoupu Hospital, Shanghai 201318, China. \\ 2. Shanghai Key Laboratory of Molecular Imaging, Shanghai University of Medicine \& Health Sciences, Shanghai 201318, China. \\ 3. Collaborative Innovation Center for Biomedicine, Shanghai University of Medicine \& Health Sciences, Shanghai 201318, China. \\ 4. Institute of Clinical Immunology, Department of Liver Diseases, Central Laboratory, Shuguang Hospital Affiliated to Shanghai University of Traditional \\ Chinese Medicine, Shanghai 200021, China. \\ 5. Laboratory of Cellular Immunity, Shuguang Hospital Affiliated to Shanghai University of Traditional Chinese Medicine, Shanghai 200021, China. \\ $\bowtie$ Corresponding authors: Hailong Wu (E-mail: wuhl@sumhs.edu.cn); Yueqiu Gao (E-mail: gaoyueqiu@hotmail.com).
}

( ) The author(s). This is an open access article distributed under the terms of the Creative Commons Attribution License (https://creativecommons.org/licenses/by/4.0/). See http://ivyspring.com/terms for full terms and conditions.

Received: 2020.11.12; Accepted: 2021.04.27; Published: 2021.10.11

\begin{abstract}
In addition to cancer-related death, malignant progression also leads to a series of symptoms and side-effects, which would detrimentally affect cancer patients' the quality of life, adversely influence their adherence to treatments, and, therefore, negatively affect their long-term survival. Acupuncture and electroacupuncture (EA), as two classic treatment methods in traditional Chinese medicine, have been widely employed to cure various diseases. Recently, the clinical application of acupuncture and EA in cancer patients has received great attention. In this review, we summarized the clinical application of acupuncture and EA in alleviating the cancer symptoms, reducing the cancer treatment-related side-effects, and relieving the cancer pain. The symptoms and side-effects discussed in this review include fatigue, insomnia, chemotherapy-associated dyspepsia syndrome (CADS), pain, xerostomia, and anxiety and depression. The underlying mechanisms of the therapeutic effects of acupuncture and EA might be related to the regulation of the mitochondrial function, coordination of the activity of the nervous system, adjustment of the production of neurotransmitters, and alleviation of the immune responses. In conclusion, acupuncture and EA have been proved to be beneficial for cancer patients. More research, however, is required to clarify the potential mechanisms behind acupuncture and EA for widespread adoption in clinical application.
\end{abstract}

Key words: acupuncture; electroacupuncture; cancer; surgery; chemotherapy; pain

\section{Introduction}

Carcinoma is the leading cause of global morbidity and mortality, so cancer prevention and treatment have become the key research topic in the medical field. In addition to death, the progression of cancer is also accompanied by a series of symptoms and side-effects that is caused by not only cancer itself but also cancer-related therapies, such as surgery, chemotherapy, radiotherapy, etc. These symptoms and side-effects will severely impact the life quality and treatment adherence of cancer patients, and, therefore, adversely affect their long-term survival. Recently, complementary and alternative medicine $(\mathrm{CAM})$, including acupuncture, deep breathing exercises, massage therapy, meditation, naturopathy, and yoga, has been increasingly adopted by cancer patients for seeking relief from cancer-associated symptoms [1]. Among them, acupuncture, a wellpracticed therapeutic approach in traditional Chinese medicine, has been implicated as an effective approach in improving cancer-associated symptoms [1].

Acupuncture has been defined as the insertion of fine needles into specific acupuncture points (acupoints) in the human body. In Eastern Asia, acupuncture has been widely employed to treat various diseases for over 2,500 years. Notably, the 
benefits of acupuncture in treating various diseases have been gradually recognized by Western society. For example, the World Health Organization (WHO) and the National Institutes of Health $(\mathrm{NIH})$ released a report on acupuncture in 2003, suggesting more than 100 types of diseases and conditions could be treated by acupuncture [2]; the NIH issued a Consensus Statement on Acupuncture to support the use of acupuncture for adult postoperative and chemotherapy-associated nausea and vomiting, postoperative dental pain, addiction, stroke rehabilitation, headache, menstrual cramps, fibromyalgia, myofascial pain, osteoarthritis, low back pain, carpal tunnel syndrome, and asthma [3]; the FDA had approved acupuncture needles for use by licensed practitioners [4]; the number of total licensed acupuncturists has increased 257\% from 1998 to 2018 in the United States [5]. Recently, a study on integrative oncology (IO) service in North America, Europe, and Australia showed that acupuncture is one of the most frequent IO services in the United States and the European Union [6].

Electroacupuncture (EA) is developed around the mid-1900s and is a modified approach of acupuncture that applying weak electronic currents through the needles after conventional acupuncture procedure. Although it is still controversial, EA has been shown to achieve similar or even better effects compared to acupuncture. Moreover, the efficacy of acupuncture mainly depends on the manipulation technique of the acupuncturist, but EA can be practiced more reproducibly and is more suitable for both basic and clinical research. In this review, we introduced the effects of acupuncture and EA on cancer-related symptoms and side-effects, the possible mechanisms behind acupuncture, and the hindrance against the wide application of acupuncture and EA in cancer-related treatment.

\section{Effects of acupuncture and EA on the symptoms and side-effects related to cancer and cancer treatment}

Cancer and cancer treatments are frequently associated with a lot of symptoms and side-effects including fatigue, insomnia, chemotherapy-associated dyspepsia syndrome (CADS), radiation-induced xerostomia (RIX), pain, vomit and nausea, cognitive impairment, distress, anxiety, depression, etc. Because some of those symptoms and side-effects are tightly related, we mainly discussed the therapeutic potential of acupuncture and EA in some of those symptoms and side-effects in this review.

\section{Fatigue}

Cancer-related fatigue (CRF) has been recognized as one of the most common cancer-related side-effects [7] and usually cannot be alleviated by adequate sleep or rest [8]. The onset of CRF commonly occurs before the cancer treatments and it frequently gets worse during the therapies [9, 10]. Although cancer patients usually will be relieved from CRF after treatment completion, near $25 \%$ to $30 \%$ of cured patients still suffer persistent fatigue for up to 10 years [11, 12]. More importantly, CRF has been recognized as a risk factor for short survival in cancer patients $[13,14]$.

The effective treatment options for CRF are limited, consisting of non-pharmacologic interventions like physical activity and psychosocial and mind-body interventions. However, a recent clinical trial, including 302 breast cancer outpatients, showed that acupuncture could significantly relieve CRF [15]. Meanwhile, EA has been shown to significantly improve fatigue in breast cancer patients treated with aromatase inhibitors [16, 17]. In addition, acupuncture has been shown to improve fatigue in lung cancer patients [18] and head and neck cancer (HNC) patients, who were subjected to chemoradiation therapy [19]. Furthermore, a meta-analysis study on ten randomized controlled trials confirmed acupuncture as an effective means for CRF [20]. Therefore, acupuncture and EA could serve as an effective and feasible approach to relieve CRF.

\section{Insomnia}

Insomnia, also called sleeplessness, is recognized as the most prevalent sleep problem worldwide. The reported prevalence of insomnia in cancer patients is up to $50 \%$, which is three times higher than that in the general population [21]. As cancer-related insomnia (CRI) is frequently viewed as a normal and transient response to cancer itself or cancer treatment, CRI is commonly neglected by both clinicians and cancer patients, leading to having a chronic insomnia symptom in a substantial proportion of cancer patients [22-24]. CRI could be treated by both pharmacologic and non-pharmacologic approaches. Hypnotic agents, including Benzodiazepines (BZDs) and non-BZDs agents, and antidepressants, such as amitriptyline, doxepin, mirtazapine, and trazodone, are commonly used in the pharmacologic treatment of CRI [25]. Although medication could improve sleep outcomes in the short-term, the significant side-effects and the concerns of drug-drug interactions limit their use. Meanwhile, as the non-pharmacologic approaches, acupuncture and EA have been shown to be effective for treating primary insomnia [26], insomnia after stroke [27], menopause insomnia [28], and chronic pain-related insomnia [29], but whether they are effective to treat CRI remains controversial. A 
previous study recruited 6 randomized controlled trials only showed a low level of evidence supporting the therapeutic advantage of acupuncture in the treatment of CRI [30]. On the contrary, other studies showed that acupuncture could produce meaningful and durable improvements in CRI in cancer survivors [31] and patients [32]. However, all of these studies suffer the weakness of a small sample size, so more adequately powered clinical trials are needed to clarify the therapeutic efficacy of acupuncture and EA in treating CRI.

\section{Chemotherapy-Associated Dyspepsia Syndrome (CADS)}

Chemotherapy is routinely employed in combination with radiotherapy, surgery, hormone therapy, or immunotherapy for treating many types of cancers. Despite the effectiveness in reducing tumor burden, chemotherapy also unavoidably raises many irreparable side-effects, such as chemotherapyassociated dyspepsia syndrome (CADS). CADS is defined as a collection of gastrointestinal symptoms after receiving chemotherapy, including early satiety, anorexia, diarrhea, nausea, and vomiting [33]. It has been reported that up to $20 \%$ of cancer patients had to postpone or even terminate potentially curative chemotherapy due to CADS [34]. Although prophylactic administration of antiemetics can reduce nausea and vomiting in 70-90\% of cancer patients [35], these antiemetics have limited effects on chemotherapy-induced early satiety, anorexia, and diarrhea.

Acupuncture has been commonly employed in China to treat gastrointestinal symptoms for thousands of years and the possible mechanisms behind might be through the altering acid secretion, GI motility, and visceral pain [36]. A previous study has demonstrated that chronic EA at ST36 can improve cisplatin-induced dyspepsia symptoms and gastric dysmotility in rats probably by enhancing vagal efferent activity and reducing satiety hormones [37]. In addition, EA at CV12 has shown to be effective to improve cisplatin treatment-induced anorexia in rats [9]. More importantly, several randomized multicenter crossover studies have shown that acupuncture could serve as a supportive antiemetic approach to reduce the medical use of antiemetics in pediatric cancer patients, who are receiving highly emetogenic chemotherapy [38, 39]. Intriguingly, a single-blind, randomized, and controlled clinical trial with a total of 142 liver cancer patients enrolled showed that transcutaneous electrical acupoint stimulation (TEAS) significantly improved cisplatininduced anorexia compared to placebo controls [40]. Therefore, evidence from both experimental studies and clinical trials supports acupuncture and EA as a feasible and effective approach to alleviate CADS.

\section{Pain Related to Cancer and Cancer Treatments}

Pain is the most common symptom of cancer and is reported in $90 \%$ of cancer patients at various progression stages [41]. Moreover, moderate to severe pain has been claimed in $40 \%$ of patients carrying early or intermediate stage cancer and $80 \%$ of cancer patients at advanced stages [42, 43]. More importantly, near $70 \%$ of cancer pain is undertreated [43].

Acupuncture and EA have been widely employed to relieve non-malignant acute and chronic pain [44]. Recently, acupuncture and EA-induced analgesic effect has been reported in both experimental cancer models and cancer patients. EA at GB30 and ST36 have been reproducibly shown to improve cancer-induced hyperalgesia in the rat bone cancer model by multiple groups [45-47]. EA at Baihui, Quchi, Neiguan, Xuehai, Zusanli, and Sanyinjiao have been shown to alleviate cancer pain in patients with advanced hepatocellular carcinoma [48]. A case report suggested that acupuncture may greatly improve the neuropathic pain induced by bone metastasis in patients with advanced cancer[49]. A recent case report study demonstrated that acupuncture is an effective and safe therapeutic option for reducing cancer pain with minimal side-effects and lowering the need for narcotic analgesics [50]. A randomized controlled clinical trial demonstrated that EA at Jiaji (Ex-B2) from T8 to T12 bilaterally could significantly relieve pancreatic cancer pain [51]. In addition to the analgesic effect on cancer pain, acupuncture and EA were also shown to improve pain caused by cancer treatments, such as surgery and chemotherapy. EA at Neimadian (Extra) and Neiguan (PC 6) have been shown to improve post-operation pain in esophageal cancer patients, who underwent thoracic surgery [52]. A previous study has shown that EA significantly inhibits allodynia and hyperalgesia in an established rat model of paclitaxel-induced peripheral neuropathy [53]. EA has been reported to improve thalidomide- or bortezomib-induced peripheral neuropathy in patients with multiple myeloma [54]. Moreover, a very recent randomized controlled pilot trial demonstrated that acupuncture could significantly improve taxane-induced peripheral neuropathy in breast cancer patients [55]. Therefore, multiple lines of evidence have indicated that acupuncture and EA could serve as complementary therapy to relieve pain that is associated with cancer and cancer treatments. 


\section{Xerostomia}

Salivary glands are significantly sensitive to radiation therapy and will be irreversibly damaged at doses higher than $50 \mathrm{~Gy}$ [56]. It has been reported that more than half of the patients, who received radiation therapy involving major salivary glands, experienced hyposalivation, a symptom also termed radiationinduced xerostomia (RIX), by the end of treatment [56]. RIX is a common and often debilitating adverse effect of radiation therapy among patients with head and neck cancer. A randomized clinical trial found that acupuncture resulted in significantly fewer and less severe RIX symptoms 1 year after the treatment compared to standard care control [57].

\section{Anxiety and Depression}

Anxiety and depression are common complications of cancer, influencing cancer patients' quality of life, their adherence to treatment, and their survival $[58,59]$. The prevalence rates of anxiety and depression in cancer patients were 19\% and $12.9 \%$ respectively [60]. The results regarding whether acupuncture could improve cancer-related anxiety and depression are controversial. A clinical trial with 47 enrolled breast cancer patients ( 23 for realacupuncture vs. 24 for sham-acupuncture) revealed that acupuncture has no significant effect to improve anxiety and depression associated with the treatment of aromatase inhibitors (AIs) [61]; whereas another clinical trial showed that EA could significantly improve anxiety and depression associated with AIs treatment in breast cancer patients [16]. Meanwhile, a clinical trial including 302 breast cancer patients showed that acupuncture could improve cancerrelated anxiety and depression [15]. It is worth noting that, in all three clinical trials above, anxiety and depression are the secondary measurement outcomes. One study, using depression as the primary outcome, illustrated that acupuncture can effectively reduce malignancy-related depression [32]. In summary, large clinical trials assessing anxiety and depression as the primary outcome need to be conducted to evaluate the role of acupuncture in cancer-related anxiety and depression.

\section{Mechanisms Related to the Therapeutic Effects of Acupuncture and EA}

Although many efforts have been made to understand the effects of acupuncture and EA in the treatment of cancer-related symptoms and side-effects, the mechanisms by which acupuncture and EA achieve therapeutic benefits remain largely unknown. The main focus has been on investigating the mechanisms of the analgesic effects of acupuncture and EA. In the early 1970s, Han's group, for the first time, strongly suggested the involvement of central chemical mediators in the analgesic effect by acupuncture. They transferred the cerebrospinal fluid of acupunctured donor rabbits into recipient rabbits and achieved analgesic effects in recipients [62]. From then on, a series of studies have demonstrated that the analgesic effects may be attributed to the neurotransmitters induced by acupuncture and EA. For example, naloxone, a specific opioid receptor antagonist, had been shown to partially reverse the analgesic effect of acupuncture on electrical stimulation-induced tooth pulp pain and chronic pain in humans and monkey subjects [63, 64]; poor EA-induced analgesia had been observed in CXBK mice that are deficient with opioid receptors [65]; protection of endogenous opioid peptides by using peptidase inhibitors could potentiate acupuncture analgesia [66, 67]. In addition, some clinical trials have demonstrated that acupuncture and EA could significantly decrease the expression of substance $P$ to relieve pain in patients with fibromyalgia [68], acute herpes zoster [69], knee osteoarthritis [70], and so on. Moreover, EA has been shown to relieve the pain of knee osteoarthritis by enhancing the response of serotonin via the upregulation of serotonin receptor 2A/C [71].

The studies on mechanisms of acupuncture and EA for treating other cancer-related symptoms and side-effects are limited. A previous study has shown that EA can improve chronic fatigue by reducing mitochondrial oxidative stress and increasing ATP synthesis [72]. Acupuncture and EA have been shown to improve insomnia by reducing the sympathetic nervous activity [73], suppressing the activation of the hypothalamic-pituitary-adrenal (HPA) axis [74, 75], increasing the levels of Gamma-aminobutyric acid (GABA) and GABA(A) receptor [76], and elevating the generation and secretion of melatonin [77]. EA at CV12 has been shown to improve CADS via an increase in the secretion of ghrelin and cholecystokinin (CCK) and a decrease in the secretion of 5-hydroxytryptamine (5-HT) into the serum $[9,78]$. In addition, chronic EA at ST36 has been shown to improve cisplatin-induced dyspepsia via modulating the production of the vagal and gastrointestinal hormones including fasting ghrelin, glucagon-like peptide-1, and peptide YY [37].

\section{Summary}

This review summarized the application of acupuncture and EA in cancer patients for improving cancer-related symptoms and side-effects, such as fatigue, insomnia, chemotherapy-associated dyspepsia syndrome (CADS), radiation-induced xerostomia (RIX), anxiety and depression, and pain (Table 1). We 
also simply introduced the potential mechanisms involved in the therapeutic effects of acupuncture and EA (Table 2). Given that the actual mechanisms of acupuncture and EA remain largely unknown, more basic and clinical studies are needed to endorse the broad clinical application of acupuncture and EA in the treatment of cancer-related symptoms and side-effects.

Table 1. The therapeutic effects of acupuncture and electroacupuncture in treatment of cancer-related symptoms and side-effects

\begin{tabular}{|c|c|c|c|c|}
\hline Therapeutic Effects & $\mathrm{AC}$ or EA & Study subjects & Acupoints & Ref \\
\hline \multirow[t]{4}{*}{ Anti-fatigue } & $\mathrm{AC}$ & Cancer-related fatigue in breast cancer & ST36, SP6, LI4, GB34, SP9 & [15] \\
\hline & EA & $\begin{array}{l}\text { Fatigue in breast cancer patients with aromatase } \\
\text { inhibitor-related arthralgia }\end{array}$ & N/A & {$[16,17]$} \\
\hline & $\mathrm{AC}$ and EA & $\begin{array}{l}\text { Fatigue in head and neck cancer patients with } \\
\text { chemoradiation therapy }\end{array}$ & $\begin{array}{l}\text { ST36, SP6, LI2, LI11, GV20, Shenmen/ear, } \\
\text { Sanjiao/ear, ST7, ST6, ST5, CV23, GB20, EX-HN3 }\end{array}$ & [19] \\
\hline & $\mathrm{AC}$ & cancer-related fatigue in lung cancer patients & LI4, REN6, ST36, KI3, SP6 & [18] \\
\hline \multirow[t]{2}{*}{ Anti-insomnia } & $\mathrm{AC}$ & Insomnia in cancer survivors & $\begin{array}{l}\text { HT7, SP6, GV20, GV24, Shenmen (Auricular), } \\
\text { Sympathetic (Auricular) }\end{array}$ & [31] \\
\hline & $\mathrm{AC}$ & Insomnia in cancer patients & $\begin{array}{l}\text { ST40, SP9, SP10, SP6, EX-HN3, DU20, } \\
\text { EX-HN1, PC6, TF4 }\end{array}$ & {$[32]$} \\
\hline \multirow{4}{*}{$\begin{array}{l}\text { Anti- chemotherapy- } \\
\text { associated dyspepsia } \\
\text { syndrome (CADS) }\end{array}$} & EA & A rodent model of dyspepsia induced by cisplatin & ST36 & [37] \\
\hline & EA & A rat model of cisplatin-induced anorexia & CV12 & [9] \\
\hline & $\mathrm{AC}$ & $\begin{array}{l}\text { Chemotherapy-induced nausea and vomiting in pediatric } \\
\text { cancer patients }\end{array}$ & $\begin{array}{l}\text { Point combinations depended on the } \\
\text { acupuncturist's decision. Most commonly used } \\
\text { points were PC6, ST36, CV12, LI4. }\end{array}$ & {$[38,39]$} \\
\hline & EA & $\begin{array}{l}\text { Liver cancer patients who receive chemotherapy via } \\
\text { intravenous infusion or transcatheter arterial } \\
\text { chemoembolization (TACE) }\end{array}$ & PC6, ST36, CV12 & {$[40]$} \\
\hline \multirow[t]{8}{*}{ Analgesia } & EA & A rat bone-cancer pain model & ST36, GB30 & {$[45-47]$} \\
\hline & EA & $\begin{array}{l}\text { Cancer pain in patients with advanced hepatocellular } \\
\text { carcinoma }\end{array}$ & GV20, LI11, PC6, ST36, SP6 & {$[48]$} \\
\hline & $\mathrm{AC}$ & Neuropathic pain induced by cancer bone metastasis & GB29, GB30, GB34, GB40, BL40, ST36 & [49] \\
\hline & EA & Pancreatic cancer pain & Ex-B2 points from T8 to T12 bilaterally & [51] \\
\hline & EA & Postoperative pain in esophageal cancer patients & EX28, PC6 & [52] \\
\hline & EA & Paclitaxel-induced peripheral neuropathy in a rat model & GB30 & {$[53]$} \\
\hline & EA & $\begin{array}{l}\text { Thalidomide/bortezomib-induced peripheral neuropathy } \\
\text { in cancer patients with multiple myeloma }\end{array}$ & $\begin{array}{l}\text { LI4, SI3, Baxie 2, Baxie 3, LV3, SP6, GB42, ST36, } \\
\text { Bafeng 2, Bafeng 3, DU20, CV4, CV6 }\end{array}$ & {$[54]$} \\
\hline & EA & $\begin{array}{l}\text { Chemotherapy induced peripheral neuropathy in breast } \\
\text { cancer survivors }\end{array}$ & SP9, ST36, SP6, K3, LR3, LI11, TW5, Baxie, Yintang & [55] \\
\hline Anti-xerostomia & $\mathrm{AC}$ & Xerostomia in patients with head and neck cancer & $\begin{array}{l}\text { Ren 24, LU 7, K6, Shenmen, Point Zero, SG 2-prime, } \\
\text { Larynx }\end{array}$ & [57] \\
\hline $\begin{array}{l}\text { Anti-anxiety and } \\
\text { depression }\end{array}$ & $\mathrm{AC}$ & depression in patients with malignant tumor & $\begin{array}{l}\text { ST 40, SP 9, SP 10, SP 6, EX-HN3, DU 20, EX-HN1, } \\
\text { PC 6, Shenmen }\end{array}$ & {$[32]$} \\
\hline
\end{tabular}

AC: Acupuncture; EA: Electro-acupuncture.

Table 2. Mechanisms related to the therapeutic effects of acupuncture and electroacupuncture

\begin{tabular}{|c|c|c|c|c|}
\hline Therapeutic Effects & $\mathrm{AC}$ or EA & Study subjects & Mechanisms & Ref \\
\hline Anti-Fatigue & EA & Rats with chronic fatigue syndrome & $\begin{array}{l}\text { Reducing mitochondrial oxidative stress and } \\
\text { increasing ATP synthesis }\end{array}$ & {$[72]$} \\
\hline \multirow[t]{4}{*}{ Anti-insomnia } & $\mathrm{AC}$ and $\mathrm{EA}$ & Insomnia in stroke patients & Reducing the sympathetic nervous activity & [73] \\
\hline & $\mathrm{AC}$ & $\begin{array}{l}\text { Insomnia in chronic stress rats or in maternal } \\
\text { separation rats }\end{array}$ & $\begin{array}{l}\text { Suppressing the activation of hypothalamic- } \\
\text { pituitary-adrenal (HPA) axis }\end{array}$ & {$[74,75]$} \\
\hline & $\mathrm{AC}$ & Insomnia rats & $\begin{array}{l}\text { Increasing the levels of Gamma-aminobutyric acid } \\
(\mathrm{GABA}) \text { and GABA(A) receptor }\end{array}$ & [76] \\
\hline & & Insomnia in anxious adult & Elevating the generation and secretion of melatonin & [77] \\
\hline \multirow[t]{2}{*}{$\begin{array}{l}\text { Anti- chemotherapy- } \\
\text { associated dyspepsia } \\
\text { syndrome (CADS) }\end{array}$} & EA & A rat model of cisplatin-induced anorexia & $\begin{array}{l}\text { Increasing the secretion of ghrelin and cholecystokinin } \\
\text { (CCK) and decreasing the secretion of } \\
\text { 5-hydroxytryptamine (5-HT) into the serum }\end{array}$ & {$[9,78]$} \\
\hline & EA & A rodent model of dyspepsia induced by cisplatin & $\begin{array}{l}\text { Modulating the production of the vagal and } \\
\text { gastrointestinal hormones }\end{array}$ & {$[37]$} \\
\hline \multirow[t]{7}{*}{ Analgesia } & $\mathrm{AC}$ and EA & $\begin{array}{l}\text { Electrical stimulation-induced tooth pulp pain in } \\
\text { humans and monkey }\end{array}$ & $\begin{array}{l}\text { Inducing endogenous opioid peptides and enhancing } \\
\text { opioid-opioid receptor signaling }\end{array}$ & {$[63,64]$} \\
\hline & EA & CXBK mice & & {$[65]$} \\
\hline & $\mathrm{AC}$ and $\mathrm{EA}$ & Pain induced by radiant heat exposure in rabbits & & {$[66,67]$} \\
\hline & $\mathrm{AC}$ & Pain in patients with fibromyalgia & Decreasing the expression of substance $\mathrm{P}$ & [68] \\
\hline & $\mathrm{AC}$ & Pain in patients with acute herpes zoster & & {$[69]$} \\
\hline & EA & Pain in patients with knee osteoarthritis & & {$[70]$} \\
\hline & EA & Pain in an Osteoarthritis Rat Model & $\begin{array}{l}\text { Enhancing response of serotonin via upregulation of } \\
\text { serotonin receptor } 2 \mathrm{~A} / \mathrm{C}\end{array}$ & {$[71]$} \\
\hline
\end{tabular}




\section{Acknowledgements}

\section{Funding}

This review was by grants from the National Natural Science Foundation of China (31870905 to H $\mathrm{Wu}, 81673938$ and 81874436 to Y Gao, 81903961 to J Le), the Scientific Program of Shanghai Municipal Health Commission (SHWJ2019211 to $\mathrm{H} \mathrm{Wu}$ ), the Shanghai Municipal Education Commission (ZZJKYX19006 to Q-Q Han), the Natural Science Foundation of Shanghai (19ZR1424000 to J Le), the National Natural Science Foundation of China (No. 81830052), Construction Project of Shanghai Key Laboratory of Molecular Imaging (18DZ2260400), Shanghai Municipal Education Commission (Class II Plateau Disciplinary Construction Program of Medical Technology of SUMHS, 2018-2020), the School-level Fund (E3-0200-21-201011-73) and the Hundred Teacher Talent Program of Shanghai University of Medicine and Health Sciences.

\section{Author Contributions}

Qiu-Qin Han drafted the manuscript. $\mathrm{Yi} \mathrm{Fu,}$ Jia-Mei Le and Yu-Jie Ma finished the two Tables. Xin-Dong Wei, Hou-Lin Ji and Haochen Jiang undertook the work of literature search. Hailong $\mathrm{Wu}$ and Yueqiu Gao, as the corresponding authors, edited the manuscript. All authors read and approved the final manuscript.

\section{Availability of data and materials}

All data generated or analyzed during this study are included in this published article.

\section{Competing Interests}

The authors have declared that no competing interest exists.

\section{References}

1. Smith ME, Bauer-Wu S. Traditional Chinese Medicine for cancer-related symptoms. Semin Oncol Nurs. 2012; 28: 64-74.

2. ACUPUNCTURE: REVIEW AND ANALYSIS OF REPORTS ON CONTROLLED CLINICAL TRIALS. World Health Organization. 2003: 87.

3. Morey SS. NIH issues consensus statement on acupuncture. American family physician. 1998; 57: 2545-6.

4. Li XM. Complementary and alternative medicine in pediatric allergic disorders. Current opinion in allergy and clinical immunology. 2009; 9: 161-7.

5. Fan AY, Stumpf SH, Faggert Alemi S, Matecki A. Distribution of licensed acupuncturists and educational institutions in the United States at the start of 2018. Complement Ther Med. 2018; 41: 295-301.

6. Grant SJ, Hunter I, Seely D, Balneaves LG, Rossi E, Bao T. Integrative Oncology: International Perspectives. Integr Cancer Ther. 2019; 18: 1534735418823266 .

7. Lawrence DP, Kupelnick B, Miller K, Devine D, Lau J. Evidence report on the occurrence, assessment, and treatment of fatigue in cancer patients. J Natl Cancer Inst Monogr. 2004: 40-50.

8. Poulson MJ. Not just tired. J Clin Oncol. 2001; 19: 4180-1.

9. Kang KS, Huh W, Bang Y, Choi HJ, Baek JY, Song JH, et al. Electroacupuncture for chemotherapy-induced anorexia through humoral appetite regulation: A preliminary experimental study. Exp Ther Med. 2019; 17: 2587-97.

10. Phillips KM, Pinilla-Ibarz J, Sotomayor E, Lee MR, Jim HS, Small BJ, et al. Quality of life outcomes in patients with chronic myeloid leukemia treated with tyrosine kinase inhibitors: a controlled comparison. Support Care Cancer. 2013; 21: 1097-103

11. Bower JE, Ganz PA, Desmond KA, Bernaards C, Rowland JH, Meyerowitz BE, et al. Fatigue in long-term breast carcinoma survivors: a longitudinal investigation. Cancer. 2006; 106: 751-8.

12. Servaes P, Gielissen MF, Verhagen S, Bleijenberg G. The course of severe fatigue in disease-free breast cancer patients: a longitudinal study. Psychooncology. 2007; 16: 787-95.

13. Quinten C, Maringwa J, Gotay CC, Martinelli F, Coens C, Reeve BB, et al. Patient self-reports of symptoms and clinician ratings as predictors of overall cancer survival. J Natl Cancer Inst. 2011; 103: 1851-8.

14. Groenvold M, Petersen MA, Idler E, Bjorner JB, Fayers PM, Mouridsen HT. Psychological distress and fatigue predicted recurrence and survival in primary breast cancer patients. Breast Cancer Res Treat. 2007; 105: 209-19.

15. Molassiotis A, Bardy J, Finnegan-John J, Mackereth P, Ryder DW, Filshie J, et al. Acupuncture for cancer-related fatigue in patients with breast cancer: a pragmatic randomized controlled trial. J Clin Oncol. 2012; 30: 4470-6.

16. Mao JJ, Farrar JT, Bruner D, Zee J, Bowman M, Seluzicki C, et al. Electroacupuncture for fatigue, sleep, and psychological distress in breast cancer patients with aromatase inhibitor-related arthralgia: a randomized trial. Cancer. 2014; 120: 3744-51.

17. Mao JJ, Bruner DW, Stricker C, Farrar JT, Xie SX, Bowman MA, et al. Feasibility trial of electroacupuncture for aromatase inhibitor--related arthralgia in breast cancer survivors. Integr Cancer Ther. 2009; 8: 123-9.

18. Cheng CS, Chen LY, Ning ZY, Zhang CY, Chen H, Chen Z, et al. Acupuncture for cancer-related fatigue in lung cancer patients: a randomized, double blind, placebo-controlled pilot trial. Support Care Cancer. 2017; 25: 3807-14.

19. Lu W, Posner MR, Wayne P, Rosenthal DS, Haddad RI. Acupuncture for dysphagia after chemoradiation therapy in head and neck cancer: a case series report. Integr Cancer Ther. 2010; 9: 284-90.

20. Zhang $\mathrm{Y}$, Lin L, Li H, Hu Y, Tian L. Effects of acupuncture on cancer-related fatigue: a meta-analysis. Support Care Cancer. 2018; 26: 415-25.

21. Palesh OG, Roscoe JA, Mustian KM, Roth T, Savard J, Ancoli-Israel S, et al. Prevalence, demographics, and psychological associations of sleep disruption in patients with cancer: University of Rochester Cancer Center-Community Clinical Oncology Program. J Clin Oncol. 2010; 28: 292-8.

22. Lindley C, Vasa S, Sawyer WT, Winer EP. Quality of life and preferences for treatment following systemic adjuvant therapy for early-stage breast cancer. J Clin Oncol. 1998; 16: 1380-7.

23. Harrison LB, Zelefsky MJ, Pfister DG, Carper E, Raben A, Kraus DH, et al. Detailed quality of life assessment in patients treated with primary radiotherapy for squamous cell cancer of the base of the tongue. Head Neck. 1997; 19: 169-75

24. Couzi RJ, Helzlsouer KJ, Fetting JH. Prevalence of menopausal symptoms among women with a history of breast cancer and attitudes toward estrogen replacement therapy. J Clin Oncol. 1995; 13: 2737-44.

25. Induru RR, Walsh D. Cancer-related insomnia. Am J Hosp Palliat Care. 2014; 31: 777-85.

26. Guo J, Wang LP, Liu CZ, Zhang J, Wang GL, Yi JH, et al. Efficacy of acupuncture for primary insomnia: a randomized controlled clinical trial. Evid Based Complement Alternat Med. 2013; 2013: 163850.

27. Lee SH, Lim SM. Acupuncture for insomnia after stroke: a systematic review and meta-analysis. BMC Complement Altern Med. 2016; 16: 228.

28. Zhang S, Jia SH, Yang LJ, Jin ZG. [Clinical trials of treatment of woman menopause insomnia due to disharmony between heart and kidney by body and auricular acupuncture]. Zhen Ci Yan Jiu. 2019; 44: 516-9.

29. Liu F, You J, Li Q, Fang T, Chen M, Tang N, et al. Acupuncture for Chronic Pain-Related Insomnia: A Systematic Review and Meta-Analysis. Evid Based Complement Alternat Med. 2019; 2019: 5381028

30. Choi TY, Kim JI, Lim HJ, Lee MS. Acupuncture for Managing Cancer-Related Insomnia: A Systematic Review of Randomized Clinical Trials. Integr Cancer Ther. 2017; 16: 135-46.

31. Garland SN, Xie SX, DuHamel K, Bao T, Li Q, Barg FK, et al. Acupuncture Versus Cognitive Behavioral Therapy for Insomnia in Cancer Survivors: A Randomized Clinical Trial. J Natl Cancer Inst. 2019; 111: 1323-31.

32. Feng $Y$, Wang XY, Li SD, Zhang Y, Wang HM, Li M, et al. Clinical research of acupuncture on malignant tumor patients for improving depression and sleep quality. J Tradit Chin Med. 2011; 31: 199-202.

33. Nelson K, Walsh D, Sheehan F. Cancer and chemotherapy-related upper gastrointestinal symptoms: the role of abnormal gastric motor function and its evaluation in cancer patients. Support Care Cancer. 2002; 10: 455-61.

34. Herrstedt J. Nausea and emesis: still an unsolved problem in cancer patients? Support Care Cancer. 2002; 10: 85-7.

35. Fonte C, Fatigoni S, Roila F. A review of olanzapine as an antiemetic in chemotherapy-induced nausea and vomiting and in palliative care patients. Crit Rev Oncol Hematol. 2015; 95: 214-21.

36. Takahashi T. Acupuncture for functional gastrointestinal disorders. J Gastroenterol. 2006; 41: 408-17.

37. Liu Y, Zhang S, Ye F, Yin J, Li S, Chen JDZ. Ameliorating effects and mechanisms of chronic electroacupuncture at ST36 in a rodent model of dyspepsia induced by cisplatin. Neurogastroenterol Motil. 2019; 31: e13474.

38. Reindl TK, Geilen W, Hartmann R, Wiebelitz KR, Kan G, Wilhelm I, et al. Acupuncture against chemotherapy-induced nausea and vomiting in pediatric oncology. Interim results of a multicenter crossover study. Support Care Cancer. 2006; 14: 172-6. 
39. Gottschling S, Reindl TK, Meyer S, Berrang J, Henze G, Graeber S, et al. Acupuncture to alleviate chemotherapy-induced nausea and vomiting in pediatric oncology - a randomized multicenter crossover pilot trial. Klin Padiatr. 2008; 220: 365-70.

40. Xie J, Chen LH, Ning ZY, Zhang CY, Chen H, Chen Z, et al. Effect of transcutaneous electrical acupoint stimulation combined with palonosetron on chemotherapy-induced nausea and vomiting: a single-blind, randomized, controlled trial. Chin J Cancer. 2017; 36: 6 .

41. Caraceni A, Portenoy RK. An international survey of cancer pain characteristics and syndromes. IASP Task Force on Cancer Pain. International Association for the Study of Pain. Pain. 1999; 82: 263-74.

42. Bruera E, Kim HN. Cancer pain. JAMA. 2003; 290: 2476-9.

43. Laird B, Colvin L, Fallon M. Management of cancer pain: basic principles and neuropathic cancer pain. Eur J Cancer. 2008; 44: 1078-82.

44. Paley CA, Johnson MI, Tashani OA, Bagnall AM. Acupuncture for cancer pain in adults. Cochrane Database Syst Rev. 2015: CD007753.

45. Zhang RX, Li A, Liu B, Wang L, Xin J, Ren K, et al. Electroacupuncture attenuates bone-cancer-induced hyperalgesia and inhibits spinal preprodynorphin expression in a rat model. Eur J Pain. 2008; 12: 870-8.

46. Mao-Ying QL, Ren DH, Mi WL, Liu Q, Wang YQ. [Analgesic effects of electroacupuncture combined with Celebrex on rats with tibial cancer pain]. Zhong Xi Yi Jie He Xue Bao. 2008; 6: 830-5.

47. Du J, Fang J, Chen Y, Wu S, Liang Y. [Parametric optimization of electroacupuncture against bone-cancer pain in rats and its intervention on mRNA expression of opioid receptor and precursor]. Zhongguo Zhen Jiu. 2015; 35: 161-8.

48. Xu L, Wan Y, Huang J, Xu F. Clinical analysis of electroacupuncture and multiple acupoint stimulation in relieving cancer pain in patients with advanced hepatocellular carcinoma. J Cancer Res Ther. 2018; 14: 99-102.

49. Su CF. Home care with acupuncture increased the quality of life in a patient with advanced cancer with neuropathic pain induced by bone metastasis: a case report. J Integr Med. 2018; 16: 208-10.

50. Irman, Helianthi DR. The Roles of Battlefield Acupuncture and Electroacupuncture in a Patient with Cancer-Related Pain. Med Acupunct. 2020; 32: 234-40.

51. Chen H, Liu TY, Kuai L, Zhu J, Wu CJ, Liu LM. Electroacupuncture treatment for pancreatic cancer pain: a randomized controlled trial. Pancreatology. 2013; 13: 594-7.

52. Zhou M, Li Y, Han X, Xing Q, Wang Y, Dong X, et al. [Clinical research of electroacupuncture on the analgesic effect of thoracic perioperative stage]. Zhongguo Zhen Jiu. 2017; 37: 705-9.

53. Meng X, Zhang Y, Li A, Xin J, Lao L, Ren K, et al. The effects of opioid receptor antagonists on electroacupuncture-produced anti-allodynia/hyperalgesia in rats with paclitaxel-evoked peripheral neuropathy. Brain Res. 2011; 1414: $58-65$.

54. Garcia MK, Cohen L, Guo Y, Zhou Y, You B, Chiang J, et al. Electroacupuncture for thalidomide/bortezomib-induced peripheral neuropathy in multiple myeloma: a feasibility study. J Hematol Oncol. 2014; 7: 41.

55. Lu W, Giobbie-Hurder A, Freedman RA, Shin IH, Lin NU, Partridge AH, et al. Acupuncture for Chemotherapy-Induced Peripheral Neuropathy in Breast Cancer Survivors: A Randomized Controlled Pilot Trial. Oncologist. 2020; 25(4):310-318.

56. Eisbruch A, Kim HM, Terrell JE, Marsh LH, Dawson LA, Ship JA. Xerostomia and its predictors following parotid-sparing irradiation of head-and-neck cancer. International journal of radiation oncology, biology, physics. 2001; 50: 695-704.

57. Garcia MK, Meng Z, Rosenthal DI, Shen Y, Chambers M, Yang P, et al. Effect of True and Sham Acupuncture on Radiation-Induced Xerostomia Among Patients With Head and Neck Cancer: A Randomized Clinical Trial. JAMA network open. 2019; 2: e1916910.

58. Stark DP, House A. Anxiety in cancer patients. British journal of cancer. 2000; 83: $1261-7$

59. Smith HR. Depression in cancer patients: Pathogenesis, implications and treatment (Review). Oncology letters. 2015; 9: 1509-14.

60. Linden W, Vodermaier A, Mackenzie R, Greig D. Anxiety and depression after cancer diagnosis: prevalence rates by cancer type, gender, and age. J Affect Disord. 2012; 141: 343-51.

61. Bao T, Cai L, Snyder C, Betts K, Tarpinian K, Gould J, et al. Patient-reported outcomes in women with breast cancer enrolled in a dual-center, doubleblind, randomized controlled trial assessing the effect of acupuncture in reducing aromatase inhibitor-induced musculoskeletal symptoms. Cancer. 2014; 120: 381-9.

62. College RGoAAPM. The role of some neurotransmitters of brain in finger-acupuncture analgesia. Sci Sin. 1974: 112-30.

63. Jiang ZY, Ye Q, Shen YT, Zhu FX, Tang SQ, Liang NI, Zeng XC. Effects of naloxone on experimental AA evaluated by sensory decision theory. Acta Zool Sin. 1978: 1-10.

64. Ha H, Tan EC, Fukunaga H, Aochi O. Naloxone reversal of acupuncture analgesia in the monkey. Exp Neurol. 1981; 73: 298-303.

65. Peets JM, Pomeranz B. CXBK mice deficient in opiate receptors show poor electroacupuncture analgesia. Nature. 1978; 273: 675-6.

66. Han JS, Zhang YZ, Zhou ZF, Tang J. Augmentation of acupuncture analgesia by peptidase inhibitor D-phenylalanine in rabbits. Acta Zool Sin. 1981; 27: 133-7.
67. Zhou ZF, Jin WQ, Han JS. Potentiation of electroacupuncture analgesia and morphine analgesia by intraventricular injection of thiophan and bestatin in the rabbit. Acta Physiol Sin. 1984; 36: 175-82.

68. Karatay S, Okur SC, Uzkeser H, Yildirim K, Akcay F. Effects of Acupuncture Treatment on Fibromyalgia Symptoms, Serotonin, and Substance P Levels: A Randomized Sham and Placebo-Controlled Clinical Trial. Pain Med. 2018; 19: 615-28.

69. Zhang Y, Li SH, Yang L, Xu QN, Pei WY, Liang ZH, et al. [Shallow Fire-needle Acupuncture Stimulation Plus Cupping Relieves Neuralgia and Downregulates Serum Substance P Level in Patients with Acute Herpes Zoster]. Zhen Ci Yan Jiu. 2018; 43: 492-4.

70. Mohammed N, Allam H, Elghoroury E, Zikri EN, Helmy GA, Elgendy A. Evaluation of serum beta-endorphin and substance $\mathrm{P}$ in knee osteoarthritis patients treated by laser acupuncture. J Complement Integr Med. 2018; 15 (2):/j/jcim.2018.15.issue-2/jcim-2017-0010/jcim-2017-0010.xml.

71. Li A, Zhang Y, Lao L, Xin J, Ren K, Berman BM, et al. Serotonin Receptor 2A/C Is Involved in Electroacupuncture Inhibition of Pain in an Osteoarthritis Rat Model. Evid Based Complement Alternat Med. 2011; 2011: 619650.

72. Dong JZ, Wei YT, Xu HY, Zhang Y, Yong RL, Xue YN, et al. [Electroacupuncture of "Zusanli" (ST 36) Raises Muscular Force by Adjusting AMPK/PGC-1 alpha Signaling in Rats with Chronic Fatigue Syndrome]. Zhen Ci Yan Jiu. 2018; 43: 335-40.

73. Lee SY, Baek YH, Park SU, Moon SK, Park JM, Kim YS, et al. Intradermal acupuncture on shen-men and nei-kuan acupoints improves insomnia in stroke patients by reducing the sympathetic nervous activity: a randomized clinical trial. Am J Chin Med. 2009; 37: 1013-21.

74. You W, Shi YJ, Han YJ, Jia BH, Tu Y. [Effect of electroacupuncture of "Baihui" (GV 20)-"Yintang" (EX-HN 3) on the expression of glucocorticoid and glucocorticoid receptor mRNA of the chronic stress model rats]. Zhen Ci Yan Jiu. 2010; 35: 261-6.

75. Park HJ, Chae Y, Kim JW, Lee H, Chung JH. Effect of acupuncture on hypothalamic-pituitary-adrenal system in maternal separation rats. Cell Mol Neurobiol. 2011; 31: 1123-7.

76. Zhou YL, Gao XY, Wang PY, Ren S. [Effect of acupuncture at different acupoints on expression of hypothalamic GABA and GABA(A) receptor proteins in insomnia rats]. Zhen Ci Yan Jiu. 2012; 37: 302-7.

77. Spence DW, Kayumov L, Chen A, Lowe A, Jain U, Katzman MA, et al. Acupuncture increases nocturnal melatonin secretion and reduces insomnia and anxiety: a preliminary report. J Neuropsychiatry Clin Neurosci. 2004; 16: 19-28.

78. Baek JY, Trinh TA, Huh W, Song JH, Kim HY, Lim J, et al. ElectroAcupuncture Alleviates Cisplatin-Induced Anorexia in Rats by Modulating Ghrelin and Monoamine Neurotransmitters. Biomolecules. 2019; 9(10):624. 